\title{
Calculation of Liquidus Temperature for Aluminum and Magnesium Alloys Applying Method of Equivalency
}

\author{
Mile B. Djurdjević, ${ }^{1}$ Srećko Manasijević, ${ }^{2}$ Zoran Odanović, ${ }^{1}$ and Natalija Dolićc \\ ${ }^{1}$ IMS Institute, Bulevar Vojvode Mišića 43, 11000 Belgrade, Serbia \\ ${ }^{2}$ Lola Institute, Kneza Višslava 70a, 11000 Belgrade, Serbia \\ ${ }^{3}$ Faculty of Metallurgy, University of Zagreb, Aleja Narodnih Heroja 3, 44103 Sisak, Croatia \\ Correspondence should be addressed to Srećko Manasijević; srecko.manasijevic@li.rs
}

Received 29 May 2013; Accepted 3 September 2013

Academic Editor: Martha Guerrero

Copyright (C) 2013 Mile B. Djurdjević et al. This is an open access article distributed under the Creative Commons Attribution License, which permits unrestricted use, distribution, and reproduction in any medium, provided the original work is properly cited.

\begin{abstract}
The purpose of this paper is to develop a mathematical equation, which will be able to accurately predict the liquidus temperature of various aluminum and magnesium cast alloys on the basis of their known chemical compositions. An accurate knowledge of liquidus temperature permits a researcher to predict a variety of physical parameters pertaining to a given alloy. The analytical expressions presented in this paper are based on the "method of equivalency." According to this concept, the influence of any alloying element on the liquidus temperature of an aluminum and/or magnesium alloy can be translated into the equivalent influence of a reference element. Silicon as a reference element has been chosen for aluminum alloys and aluminum for magnesium alloys. The sum of the equivalent concentrations for other elements, when added to the influence of the actual reference element is used to calculate the liquidus temperature of the alloy. The calculated liquidus temperatures for wide ranges of alloy chemical compositions show a good correlation with corresponding measured liquidus temperatures.
\end{abstract}

\section{Introduction}

In order to predict the various physical parameters of a solidifying aluminum and magnesium alloys (e.g., fraction solid), the liquidus temperatures of these alloys must be known with the highest possible degree of accuracy. Unfortunately, only few equations are reported in the literature that relate the compositions of many commercially important nonferrous $[1,2]$ and ferrous [3] alloys to their liquidus temperatures. Moreover, some of these equations are not sufficiently verified by experimental data. For the binary aluminum and magnesium alloys, liquidus temperature/composition relations can easily be derived from highly accurate binary diagrams. These are based on experimental data obtained under equilibrium solidification conditions $[4,5]$.

The Al-Si phase diagram is the base component system for the Al-Si series of alloys. As Figure 1 shows, it is a binary eutectic type phase diagram with limited aluminum and silicon solubility. The melting temperature of pure aluminum is $660^{\circ} \mathrm{C}$. The solubility of silicon in the aluminum melt reaches a maximum of $1.6 \mathrm{wt} . \%$ at the $577^{\circ} \mathrm{C}$ eutectic temperature. The maximum solubility of aluminum in silicon at the eutectic temperature is still questionable, and according to some literature data, it is approximately $0.015 \mathrm{wt} . \%$ [6]. The concentration of silicon, which corresponds to the eutectic reaction, is still not accurately defined or accepted among researchers, despite the fact that this diagram has been investigated often. In the available literature the following values for eutectic concentration of silicon were found: 11.9 wt.\% [7], $12.2 \mathrm{wt} . \%$ [6], 12.3 wt.\% [8] and $12.6 \mathrm{wt} . \%$ [9] In this work the value of $12.3 \mathrm{wt} . \%$. of $\mathrm{Si}$ will be used as the eutectic concentration of silicon as well as $577^{\circ} \mathrm{C}$ as the temperature at which eutectic reaction occurs.

The cast aluminum-silicon alloys are widely used in many automotive components. These alloys are characterized by their low density, light weight, relative low melting temperatures, negligible gas solubility (with the exception of hydrogen), excellent castability, good corrosion resistance, electrical, and thermal conductivity and good machinability. Major alloying elements, $\mathrm{Si}, \mathrm{Cu}$, and $\mathrm{Mg}$, are primarily 


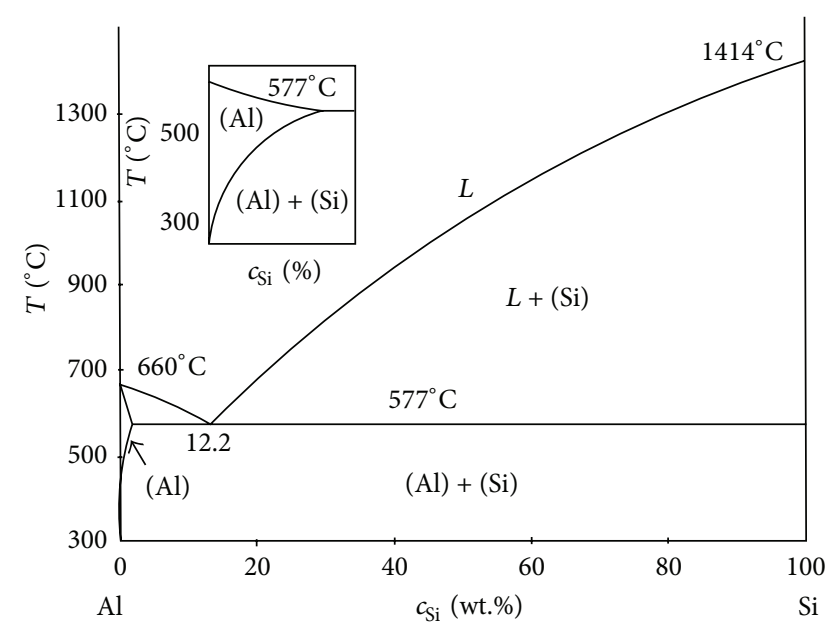

Figure 1: The Al-Si phase diagram [6].

responsible for defining the microstructure of the aluminum alloy.

$\mathrm{Mg}-\mathrm{Al}$ alloys are light metallic structural materials with a unique combination of properties, which are very attractive in such applications as the automobile, aerospace, and electronics industries. The use of magnesium alloys has become significant due to a one-third lower density of magnesium compared with aluminum, improved damping ability, a higher resistance to corrosion and better mechanical properties. In lightweight magnesium alloys, aluminum constitutes the main alloying element, chiefly because of its low price, availability, low density, and the advantageous effects on corrosion, and strength properties. Figure 2 shows the binary $\mathrm{Mg}$-Al phase diagram with limited $\mathrm{Al}$ and $\mathrm{Mg}$ solubility [10]. The melting temperature of pure magnesium is $650^{\circ} \mathrm{C}$. The solubility of magnesium in the aluminum melt reaches a maximum of 18.9 at. $\%$ at the $450^{\circ} \mathrm{C}$ eutectic temperature. The maximum solubility of aluminum in magnesium at the eutectic temperature is 11.8 at.\% [11]. In this work, the value of $32.0 \mathrm{wt} . \%$ of $\mathrm{Al}$ will be used as the eutectic concentration of aluminum as well as $473^{\circ} \mathrm{C}$ as the temperature at which eutectic reaction occurs.

The modeling and control of the casting processes have remained a topic of active interest for several decades, and the availability of numerous software packages (MAGMA [12], Thermo-Calc [13], Pandat [14], FactSage [15], Pro-Cast [16], Calphad [17], WinCast [18], etc.) on the market a good indication of the interest that casting industries and researchers have in this field. Most of the data used in the above listed software packages are based on binary or multicomponent phase diagrams, but unfortunately, except for binary diagrams, many of the ternary or higher order phase diagrams are still not accurate enough for this purpose. Keeping in mind that most aluminum and magnesium binary systems are very well established, the transferring of a multicomponent system into a well-known $\mathrm{Al}-X_{i}$ "quasi-binary" system has a great industrial and research potential. This type of system could be used to calculate several thermo-physical and solidification process parameters of multicomponent

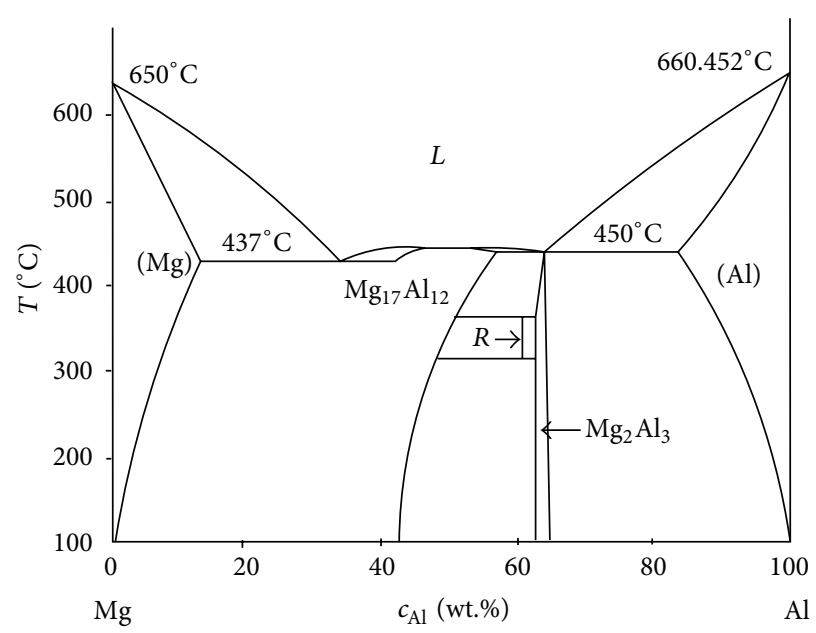

Figure 2: The Mg-Al binary phase diagram [10].

aluminum alloys in either cast or melt treated conditions. In order to calculate the various thermophysical and metallurgical parameters of solidifying aluminum casting alloys, the characteristic solidification temperatures of the alloys must be known with the highest possible degree of accuracy.

The purpose of this paper is to develop the general method for the calculation of the characteristic liquidus temperatures of the multicomponent aluminum-silicon and magnesium-aluminum alloys based on their known chemical composition. The accuracy of the developed algorithms will be determined by comparing the calculated values of the liquidus temperatures with the measured values obtained using the thermal analysis technique as with the calculated values obtained using Thermo-Calc software program.

\section{Modeling the Liquidus Temperature of Multicomponent Al and Mg Alloys}

2.1. Development of the Algorithm of Equivalency. Figures 3 and 4 show several phase diagrams of selected aluminum and magnesium binary alloys. From most of them, it is visible that their liquidus temperatures decrease uniformly with the increase in the amount of the added alloying element and reach the minimum at the corresponding eutectic composition. Mathematically, the liquidus line of any eutectic binary $\mathrm{Al}-X_{i}$ and/or $\mathrm{Mg}-X_{i}$ phase diagrams from Figures 3 and 4 can be accurately expressed by the second order polynomial as follows:

$$
\begin{gathered}
T_{\mathrm{liq}}^{\mathrm{Al}-X_{i}}=A-B X_{i}-C X_{i}^{2}, \\
T_{\mathrm{liq}}^{\mathrm{Mg}-X_{i}}=A-B X_{i}-C X_{i}^{2},
\end{gathered}
$$

where $T_{\text {liq }}^{\mathrm{Al}-X_{i}}$ and $T_{\text {liq }}^{\mathrm{Mg}-X_{i}}$ are the liquidus temperatures of the observed binary system in ${ }^{\circ} \mathrm{C}, X_{i}$ is the amount of the alloying element in wt.\%, $A$ is the melting point of pure aluminum/magnesium, $660^{\circ} \mathrm{C}$ and $650^{\circ} \mathrm{C}$, respectively, and $B$, and $C$ are polynomial coefficients. 


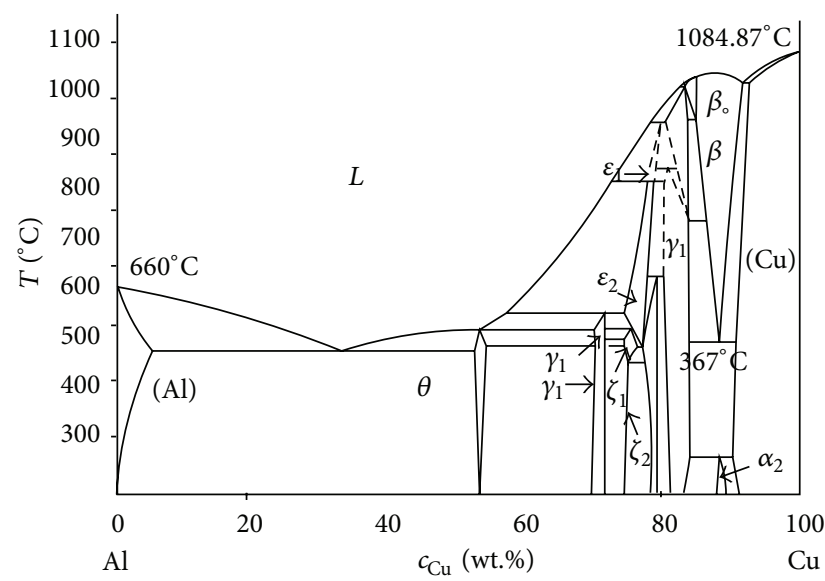

(a)

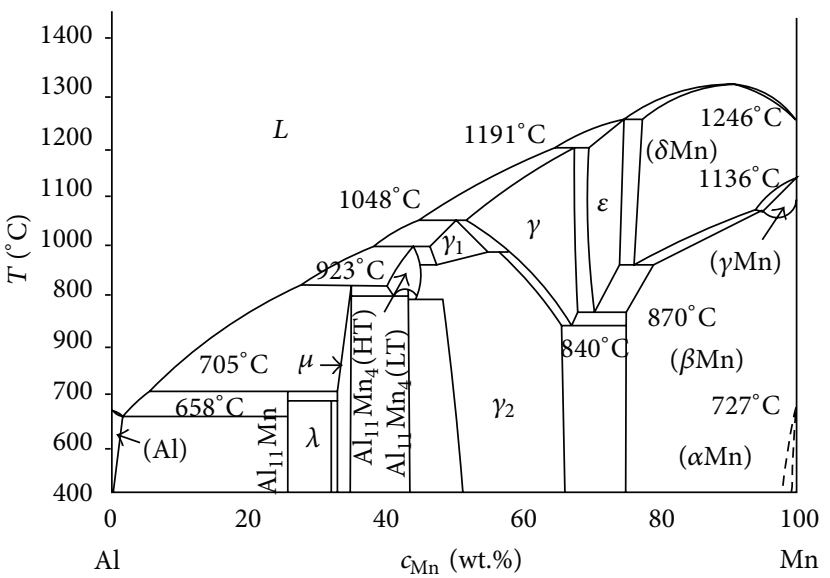

(c)

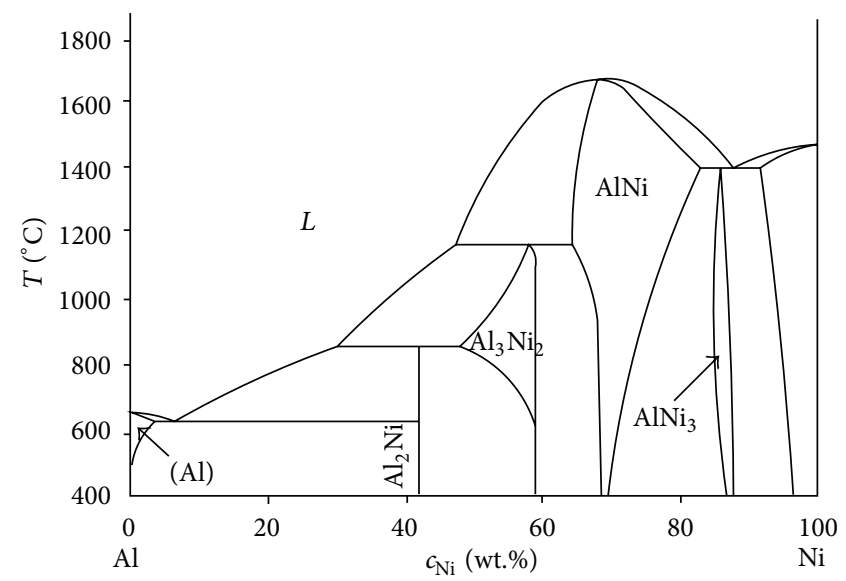

(b)

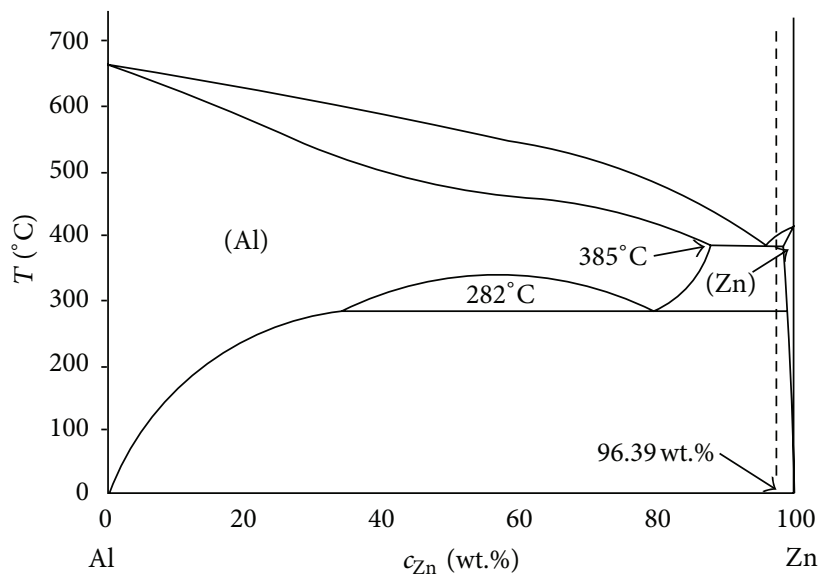

(d)

FIgURE 3: Binary phase diagrams of major aluminum alloying elements [13].

Therefore, the liquidus line for the Al-Si binary system can be expressed, respectively, as follows:

$$
T_{\text {liq }}^{\mathrm{Al}-\mathrm{Si}}=660.0-6.11 \mathrm{Si}-0.057 \mathrm{Si}^{2} .
$$

Applying the same approach from (1a) and (1b), the liquidus line of the $\mathrm{Mg}$-Al binary system can be written as

$$
T_{\mathrm{liq}}^{\mathrm{Mg}-\mathrm{Al}}=650.0-4.987 \mathrm{Al}-0.047 \mathrm{Al}^{2} .
$$

The visual analysis of the two liquidus lines of the binary systems, $\mathrm{Al}$ reference element and $\mathrm{Al}-X_{i}$ as presented in Figure 5, shows that the "equivalent effect" on the liquidus temperature of the aluminum alloy can be obtained by using "equivalent" concentrations of the reference element and $X_{i}$ alloying elements.

This means that the influence of any alloying $X_{i}$ element in the aluminum or magnesium melt on its liquidus temperature can be expressed as the effect of an "equivalent amount" of reference element, expressed in wt.\%. Silicon as a major alloying element for Al-Si series of alloys was chosen as the reference element. It is also known to have the most significant influence on the casting properties of Al-Si family of alloys (e.g., fluidity, latent heat, and shrinkage).

In lightweight magnesium alloys, aluminum is the mainly alloying element, chiefly because of its low price, availability, low density, and the advantageous effects on corrosion and strength properties. The AZ91 alloy (contains about 9 wt.\% $\mathrm{Al}$ and $1 \mathrm{wt} . \% \mathrm{Zn}$ ) is the most widely used magnesium alloy exhibiting a good combination of high strength at room temperature, good castability, and excellent corrosion resistance. Therefore, by magnesium alloys, aluminum has been chosen as a reference element.

The isothermal concentration difference between the reference element ( $\mathrm{Si}$ or $\mathrm{Al}$ ) and the $X_{i}$ alloying elements can be mathematically expressed as follows:

$$
\begin{aligned}
& \mathrm{Si}_{\mathrm{EQ}, @ T=\text { CONSTANT }}^{X_{i}}=\mathrm{Si}(\text { wt. } \%)-X_{i}(\text { wt. } \%), \\
& \mathrm{Al}_{\mathrm{EQ}, @ T=\text { CONSTANT }}^{X_{i}}=\mathrm{Al}(\text { wt. } \%)-X_{i}(\text { wt. } \%) .
\end{aligned}
$$

Taking into consideration the whole temperature range between the melting temperature of the pure reference element ( $\mathrm{Si}$ or $\mathrm{Al})$ and the corresponding eutectic temperature 


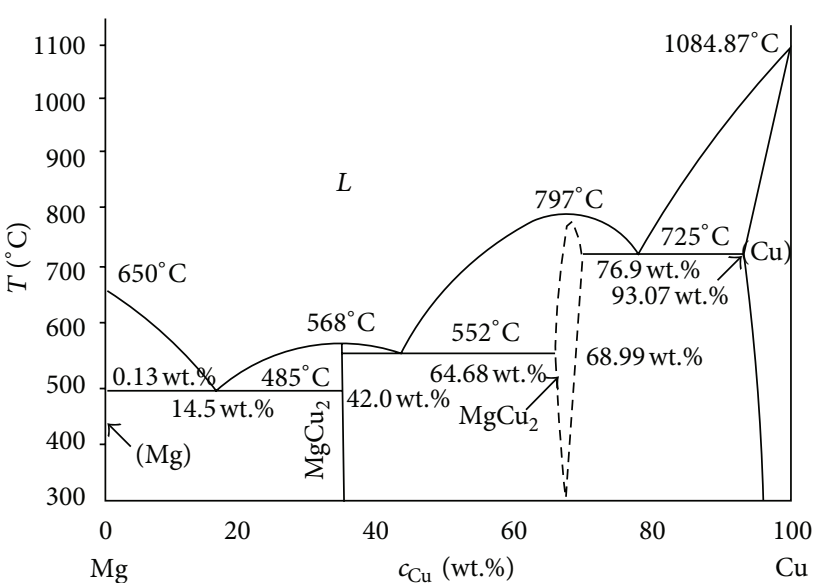

(a)

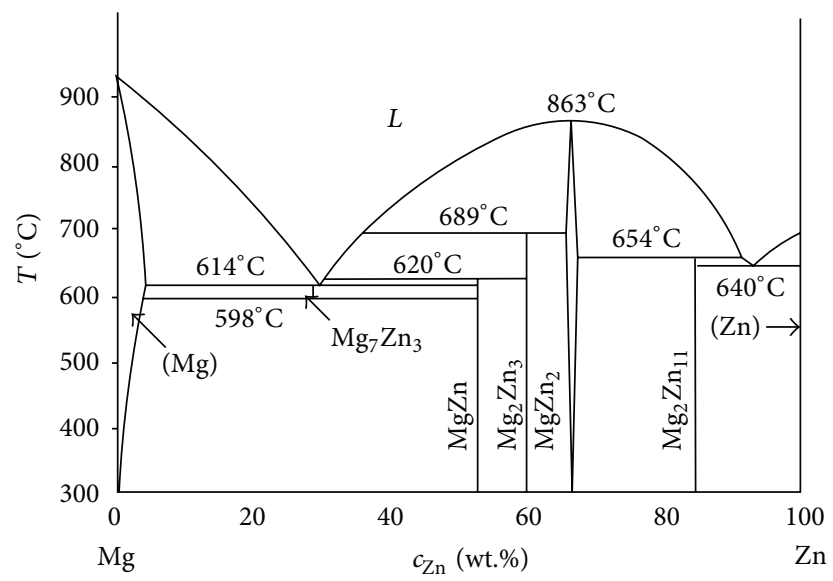

(c)

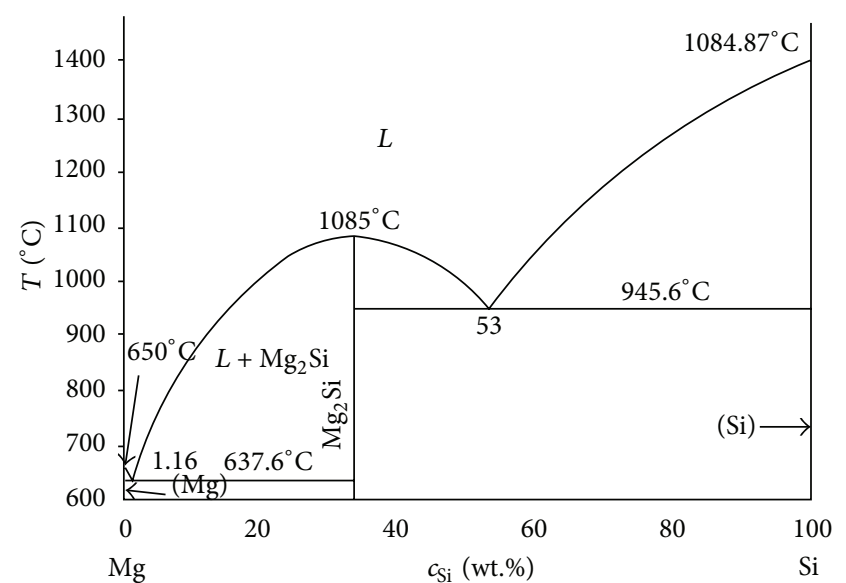

(b)

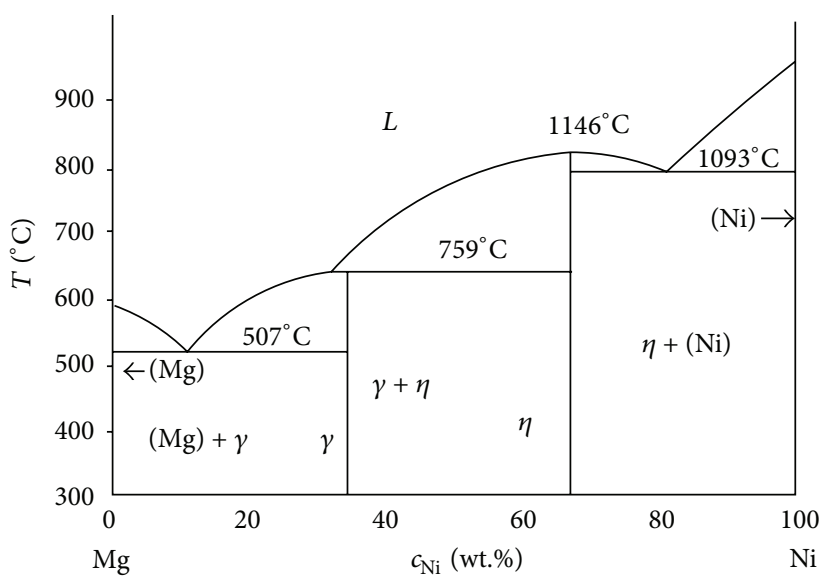

(d)

Figure 4: Binary phase diagrams of selected magnesium alloys [10, 13].

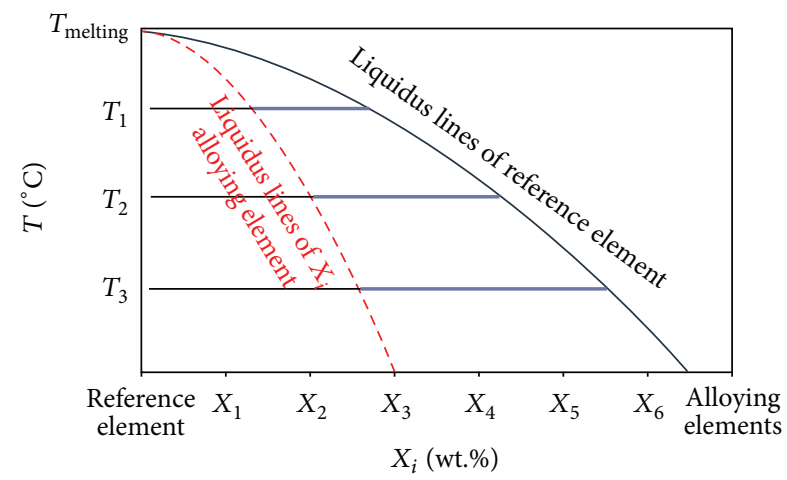

FIgURE 5: Superimposed liquidus lines of the reference element and $X_{i}$ alloying elements in any binary system.

of an observed binary alloy (Al-Si or Mg-Al), the following relationship can be established between $\mathrm{Si}_{\mathrm{EQ}}^{X_{i}}, \mathrm{Al}_{\mathrm{EQ}}^{X_{i}}$ and the concentration of the alloying element $X_{i}$ :

$$
\mathrm{Si}_{\mathrm{EQ}}^{X_{i}}=a_{\mathrm{o}}^{X_{i}}+b_{\mathrm{o}}^{X_{i}} X_{i}+c_{o}^{X_{i}} X_{i}^{2}
$$

$$
\mathrm{Al}_{E Q}^{X_{i}}=a_{o}^{X_{i}}+b_{o}^{X_{i}} X_{i}+c_{o}^{X_{i}} X_{i}^{2}
$$

where $\mathrm{Si}_{\mathrm{EQ}}^{X_{i}}$ is the silicon equivalent for any alloying element expressed in wt.\%, $\mathrm{Al}_{\mathrm{EQ}}^{X_{i}}$ is the aluminum equivalent for any alloying element expressed in wt.\%, $a_{\mathrm{o}}^{X_{i}}, b_{\mathrm{o}}^{X_{i}}$, and $c_{\mathrm{o}}^{X_{i}}$ are polynomial coefficients of the quadratic equation which describe the relationship between $\mathrm{Si}_{\mathrm{EQ}, @ T=C O N S T A N T}^{X_{i}}$ or $\mathrm{Al}_{\mathrm{EQ}, @ T=\mathrm{CONSTANT}}^{X_{i}}$ and considered the alloying elements for at least three various temperatures, and $X_{i}$ is the concentration of the alloying elements in wt.\%.

The coefficients for the particular alloying elements $\left(a_{0}\right.$, $b_{0}$, and $c_{0}$ ) from (4a) and (4b) are found in Table 1.

The $\mathrm{Si}_{\mathrm{EQ}}$ and/or $\mathrm{Al}_{\mathrm{EQ}}^{X_{i}}$ for the alloying elements as well as for some impurity elements can be determined as the sum of individual contributors $\left(\sum \mathrm{Si}_{\mathrm{EQ}}^{X_{i}}, \sum \mathrm{Al}_{\mathrm{EQ}}^{X_{i}}\right)$ plus the effect of the silicon/aluminum itself, and can be expressed as follows:

$$
\begin{aligned}
\mathrm{Si}_{\mathrm{EQ}} & =\mathrm{Si}+\sum \mathrm{Si}_{\mathrm{EQ}}^{X_{i}}, \\
\mathrm{Al}_{\mathrm{EQ}} & =\mathrm{Al}+\sum \mathrm{Al}_{\mathrm{EQ}}^{X_{i}}
\end{aligned}
$$


TABLE 1: Polynomial coefficients for the $\mathrm{Si}_{\mathrm{EQ}}^{X_{i}}$ and $\mathrm{Al}_{\mathrm{EQ}}^{X_{i}}$ function ((4a) and $(4 b))$.

\begin{tabular}{lcccccc}
\hline Elements & \multicolumn{3}{c}{ Coefficients for the $\mathrm{Si}_{\mathrm{EQ}}^{\mathrm{Xi}}$} & \multicolumn{3}{c}{ Coefficients for the $\mathrm{Al}_{\mathrm{EQ}}^{\mathrm{Xi}}$} \\
$X_{i}$ & $a_{o}$ & $b_{o}$ & $c_{o}$ & $a_{o}$ & $b_{o}$ & $c_{o}$ \\
\hline $\mathrm{Si}$ & 1.0 & 0.0 & 0.0 & 0.0 & 0.5111 & -0.1458 \\
$\mathrm{Al}$ & & & & 1.0 & 0.0 & 0.0 \\
$\mathrm{Cu}$ & 0.0 & 0.35 & -0.027 & 0.0 & -0.4161 & 0.0069 \\
$\mathrm{Mg}$ & 0.0 & 0.0258 & 0.0088 & & & \\
$\mathrm{Zn}$ & 0.0 & 0.1227 & -0.0002 & 0.0 & -0.4983 & 0.0047 \\
$\mathrm{Ni}$ & 0.0 & 0.5644 & -0.0285 & & & \\
$\mathrm{Mn}$ & 0.0 & 0.8221 & -0.0349 & & & \\
$\mathrm{Fe}$ & 0.0 & 0.6495 & 0.0003 & & & \\
$\mathrm{Y}$ & & & & 0.0 & -0.5695 & 0.0040 \\
\hline
\end{tabular}

The characteristic liquidus temperatures for multi component $\mathrm{Al}-\mathrm{Si}$ and $\mathrm{Mg}-\mathrm{Al}$ series of alloys can be calculated using following equations:

$$
\begin{gathered}
T_{\mathrm{LIQ}}^{\mathrm{Al}-\mathrm{Si} \sum X_{i}}=660.0-6.110 \mathrm{Si}_{\mathrm{EQ}}-0.057 \mathrm{Si}_{\mathrm{EQ}}^{2}, \\
T_{\mathrm{LIQ}}^{\mathrm{Mg}-\mathrm{Al} \sum X_{i}}=650.0-4.987 \mathrm{Al}_{\mathrm{EQ}}-0.047 \mathrm{Al}_{\mathrm{EQ}}^{2} .
\end{gathered}
$$

Equations (6a) and (6b) are valid for the following concentrations of key elements (expressed in wt.\%):

For aluminum alloys,

$$
\mathrm{Si} \leq 12.6, \quad \mathrm{Cu} \leq 10.0, \quad \mathrm{Mg} \leq 10.0,
$$

$\mathrm{Zn} \leq 10.0, \quad \mathrm{Ni} \leq 2.0, \quad \mathrm{Mn} \leq 2.0, \quad \mathrm{Fe} \leq 1.0$.

For magnesium alloys,

$$
\begin{gathered}
\mathrm{Al} \leq 32.0, \quad \mathrm{Zn} \leq 45.0, \quad \mathrm{Si} \leq 1.5, \\
\mathrm{Cu} \leq 33.0, \quad \mathrm{Y} \leq 24.0 .
\end{gathered}
$$

\section{Results and Discussion}

The validity of the calculation procedure presented above was determined by comparing the calculated liquidus temperatures with the experimentally determined and computed (using Thermo-Calc software package) liquidus temperatures of aluminum and magnesium alloys. These comparisons are presented in Tables 2 and 3.

The slight discrepancies between measured and calculated values of liquidus temperatures (Tables 2 and 3) for aluminum and magnesium hypoeutectic cast alloys are related to the fact that the interaction among alloying elements from aluminum and magnesium melts has not been taken into consideration in (6a) and (6b). The analytical approach of this work is based on binary alloying systems (Figures 3 and 4), and no other interactions between three or more elements have been taken into consideration for the $\mathrm{Si}_{\mathrm{EQ}}$ and $\mathrm{Al}_{\mathrm{EQ}}$ methods. By allowing these parameters of interaction among of at least three elements (taken from ternary systems) from aluminum and magnesium melts might bring the calculated values closer to the measured ones.

Figure 6 depicts a plot of the predicted liquidus temperature for each of the aluminum and magnesium alloys presented in Tables 2 and 3 versus their experimentally determined counterparts. Measured liquidus temperatures have been determined experimentally using the thermal analysis technique. According to the available literature data, the accuracy of the applied thermal analysis technique was between \pm 0.5 and $1^{\circ} \mathrm{C}$. All calculated liquidus temperatures have been computed using the method of equivalency expressed in this work through (6a) and (6b).

Figure 6 together with Table 4 demonstrate the pretty fair accuracy of the predictions made by the procedure developed in this study in comparison with the measured liquidus temperatures taken from the literature and calculated with Thermo-Calc software.

Table 4 displays that both approaches (the method of equivalency and the Thermo-Calc software) are used to calculate the liquidus temperatures of $\mathrm{Al}$ and $\mathrm{Mg}$ alloys according to $R^{2}$ criteria which shows pretty fair predictions. Statistical analysis reveals that application of (6a) for the calculation of liquidus temperatures results in lower standard deviations and lower scatter (minimum and maximum values) in the predictions compared to the results obtained using Thermo-Calc software package. Regarding Mg alloys, applying either (6b) or Thermal-Calc software, the statistical analysis shows almost the same results, that is, the same accuracy in comparison to measured liquidus temperature independent from applied procedures.

The main advantage of the method of equivalency has been recognized in its simplicity and straightforward application. Using chemical compositions of corresponding aluminum and/or magnesium alloys, their liquidus temperatures can be calculated using known polynomial coefficients for the $\mathrm{Si}_{\mathrm{EQ}}$ and $\mathrm{Al}_{\mathrm{EQ}}$. This method can be in the future simply applied for any multicomponent metallic system that satisfies the following assumptions.

(1) The melting point of reference element is known and constant.

(2) The considered binary systems (reference element$X_{i}$ ) are eutectic or peritectic.

(3) Any addition of alloying elements to the reference element decreases the liquidus temperature to its eutectic temperature (peritectic type of reaction negative sign needs to be inserted in front the of corresponding polynomial coefficients from (4a) and (4b)).

(4) For the multicomponent alloys, the equivalent concentration of the reference element needs to be considered as additive.

The accuracy of the calculated liquidus temperature in the proposed model (6a) and (6b) is dependent solely on the accuracy of the coefficients, by means of which the corresponding alloy content is converted into an equivalent silicon/aluminum weight percent. However, these coefficients are derived from the liquidus lines in the respective binary systems, and their reliability is closely related to the accuracy 
TABle 2: Chemical composition of aluminum alloys (wt.\%) calculated liquidus temperatures using (6a), Thermo-Calc, and the measured.

\begin{tabular}{|c|c|c|c|c|c|c|c|c|c|c|}
\hline \multirow{2}{*}{ Number } & \multicolumn{7}{|c|}{ Chemical composition, wt.\% } & \multicolumn{3}{|c|}{$T_{\mathrm{LIQ}} /{ }^{\circ} \mathrm{C}$} \\
\hline & $\mathrm{Si}$ & $\mathrm{Cu}$ & $\mathrm{Mg}$ & $\mathrm{Zn}$ & $\mathrm{Fe}$ & $\mathrm{Mn}$ & $\mathrm{Ti}$ & Equation (6a) & Thermo-Calc & Measured [Ref] \\
\hline 1 & 7.03 & 0.01 & 0.30 & 0.019 & 0.08 & & 0.12 & 614.2 & 616 & $614.2[19]$ \\
\hline 2 & 6.80 & 0.04 & 0.35 & 0.01 & 0.08 & & 0.15 & 615.8 & 618 & $615.8[9]$ \\
\hline 3 & 7.80 & & & & & & & 609.3 & 611 & $609.4[7]$ \\
\hline 4 & 5.80 & 0.05 & & & & & & 623.1 & 624 & $623.1[20]$ \\
\hline 5 & 7.00 & 0.05 & 0.51 & 0.02 & 0.05 & 0.01 & 0.05 & 614.5 & 615 & $614.5[21]$ \\
\hline 6 & 5.75 & 3.01 & 0.30 & 0.04 & 0.31 & 0.05 & 0.07 & 616.2 & 614 & $616.2[22]$ \\
\hline 7 & 5.10 & 2.93 & 0.23 & 0.04 & 0.31 & 0.05 & 0.17 & 620.7 & 621 & $620.7[23]$ \\
\hline 8 & 7.02 & 0.24 & 0.37 & 0.17 & 0.18 & 0.03 & 0.14 & 613.1 & 615 & $613.1[24]$ \\
\hline 9 & 6.91 & 0.24 & 0.39 & 0.15 & 0.18 & 0.03 & 0.14 & 613.8 & 616 & $613.8[25]$ \\
\hline 10 & 4.85 & 1.03 & 0.14 & 0.01 & 0.09 & 0.01 & 0.06 & 626.6 & 628 & $626.8[25]$ \\
\hline 11 & 5.01 & 2.06 & 0.14 & 0.01 & 0.09 & 0.01 & 0.06 & 622.8 & 623 & $623.8[25]$ \\
\hline 12 & 4.94 & 2.98 & 0.21 & 0.01 & 0.07 & 0.01 & 0.06 & 620.0 & 621 & $622.9[25]$ \\
\hline 13 & 4.89 & 3.85 & 0.16 & 0.01 & 0.09 & 0.01 & 0.09 & 618.3 & 619 & $622.4[25]$ \\
\hline 14 & 5.90 & 1.07 & 0.14 & 0.01 & 0.07 & 0.01 & 0.06 & 622.4 & 620 & 619.7 [25] \\
\hline 15 & 5.91 & 1.83 & 0.15 & 0.01 & 0.11 & 0.01 & 0.06 & 618.9 & 618 & $618.1[25]$ \\
\hline 16 & 5.82 & 3.03 & 0.15 & 0.01 & 0.06 & 0.01 & 0.06 & 614.8 & 615 & $617.1[25]$ \\
\hline 17 & 7.13 & 0.96 & 0.28 & 0.01 & 0.12 & 0.01 & 0.06 & 613.3 & 612 & 611.2 [25] \\
\hline 18 & 7.05 & 1.98 & 0.28 & 0.01 & 0.13 & 0.01 & 0.08 & 610.3 & 609 & 609.8 [25] \\
\hline 19 & 6.95 & 3.05 & 0.26 & 0.01 & 0.14 & 0.01 & 0.08 & 607.4 & 607 & $608.8[25]$ \\
\hline 20 & 6.75 & 4.38 & 0.29 & 0.01 & 0.12 & 0.01 & 0.09 & 604.6 & 603 & $608.9[25]$ \\
\hline 21 & 8.03 & 1.09 & 0.28 & 0.01 & 0.14 & 0.01 & 0.09 & 600.7 & 605 & $604.5[25]$ \\
\hline 22 & 8.14 & 1.93 & 0.27 & 0.01 & 0.12 & 0.01 & 0.08 & 601.7 & 602 & $602.2[25]$ \\
\hline 23 & 8.03 & 2.96 & 0.29 & 0.01 & 0.14 & 0.01 & 0.09 & 600.5 & 599 & $601.3[25]$ \\
\hline 24 & 7.84 & 4.31 & 0.31 & 0.01 & 0.14 & 0.01 & 0.09 & 596.8 & 595 & $601.2[25]$ \\
\hline
\end{tabular}

TABLE 3: Chemical composition of magnesium alloys (wt.\%) calculated liquidus temperatures using (6b), Thermo-Calc, and the measured.

\begin{tabular}{|c|c|c|c|c|c|c|c|c|c|}
\hline \multirow{2}{*}{ Number } & \multirow{2}{*}{ Alloy } & \multicolumn{5}{|c|}{ Chemical composition, wt.\% } & \multicolumn{3}{|c|}{$T_{\mathrm{LIQ}} /{ }^{\circ} \mathrm{C}$} \\
\hline & & $\mathrm{Al}$ & $\mathrm{Zn}$ & $\mathrm{Ca}$ & $\mathrm{Mn}$ & $\mathrm{Cu}$ & Equation $(6 b)$ & Thermo-Calc & Measured [Ref] \\
\hline 1 & AZC911 & & & & & & 603.1 & 592 & $600.0[26]$ \\
\hline 2 & AMC502 & 5.11 & & 1.63 & 0.32 & & 623.1 & 615 & $625.0[26]$ \\
\hline 3 & AMC503 & 5.37 & & 2.89 & 0.30 & & 621.7 & 610 & $615.0[26]$ \\
\hline 4 & AZ62 & 6.61 & 1.32 & & 0.24 & & 618.2 & 610 & $608.0[27]$ \\
\hline 5 & AZ91 & 8.67 & 0.63 & & 0.21 & & 604.0 & 601 & $598.0[27]$ \\
\hline 6 & AM60 & 6.50 & 0.22 & & 0.13 & & 616.1 & 615 & $615.0[28]$ \\
\hline 7 & AZ91 & 9.70 & 0.35 & & 0.13 & 0.10 & 598.3 & 596 & $595.0[28]$ \\
\hline 8 & AM50 & 5.25 & 0.01 & & 0.37 & & 622.5 & 622 & 625.1 [29] \\
\hline 9 & AZ91D & 9.71 & 0.35 & & 0.15 & 0.03 & 598.2 & 596 & $598.0[18]$ \\
\hline 10 & AM60B & 6.51 & 0.20 & & 0.24 & 0.01 & 616.0 & 615 & $615.0[18]$ \\
\hline 11 & AM50A & 5.41 & 0.21 & & 0.26 & 0.01 & 622.1 & 621 & $620.0[18]$ \\
\hline 12 & AM20 & 2.50 & 0.20 & & 0.33 & 0.08 & 638.0 & 636 & $638.0[18]$ \\
\hline 13 & $\mathrm{AE} 42$ & 4.51 & 0.20 & & 0.15 & 0.01 & 627.0 & 626 & $626.0[18]$ \\
\hline
\end{tabular}

with which the liquidus curves are experimentally determined and numerically fitted. Therefore, some inaccuracy is also observed by applying this method. In order to exclude this source of error, a reexamination of the liquidus lines on the silicon/aluminum rich sides of the respective binary systems, or even better for the ternary $\mathrm{Al}-\mathrm{Si}-X_{i} / \mathrm{Mg}-\mathrm{Al}-X_{i}$ systems, would be necessary.
The model has been developed using binary phase diagrams of $\mathrm{Al}-X_{i}$ and $\mathrm{Mg}-X_{i}$ alloys. For all the considered binary phase diagrams, the liquidus lines have been mathematically described until their corresponding eutectic concentrations. The concentration limits for the key elements have been established by either using the maximal concentration of key element at eutectic temperature (for major 


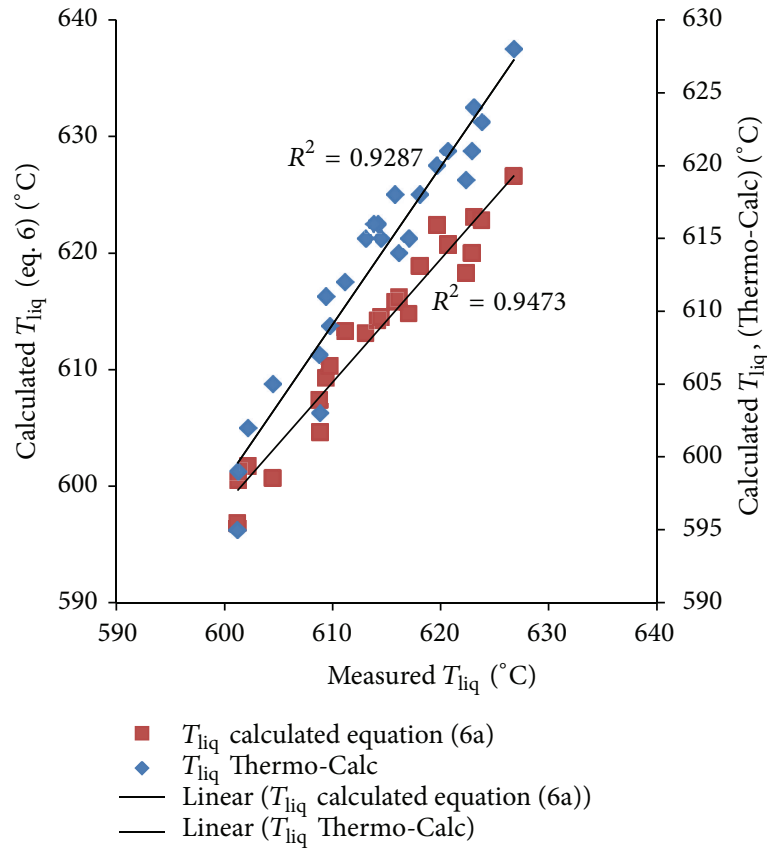

(a)

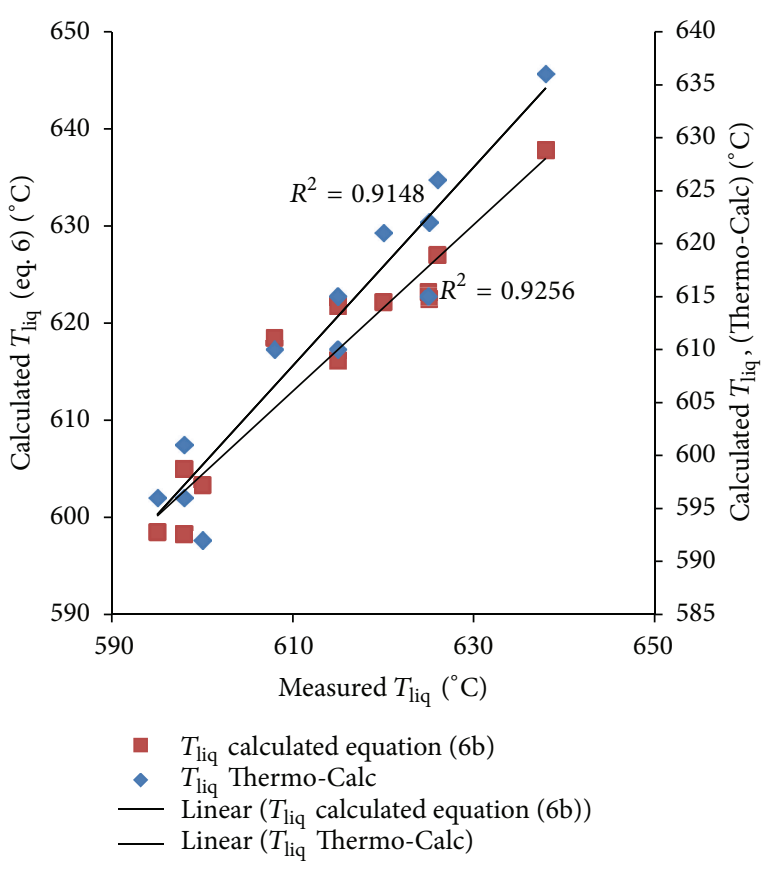

(b)

FIGURE 6: Predicted versus measured liquidus temperatures calculated applying the method of equivalency, (a) aluminum alloys (6a) and (b) magnesium alloys (6b).

TABLE 4: Regression coefficients, standard deviations and average values of differences calculated between measured and analytically determined liquidus temperatures using method equivalency and Thermo-Calc software.

\begin{tabular}{lcccc}
\hline \multirow{2}{*}{ Statistical data } & \multicolumn{2}{c}{ Al-alloys } & \multicolumn{2}{c}{ Mg-alloys } \\
& $\begin{array}{c}\text { Equation } \\
(6 \mathrm{a})\end{array}$ & $\begin{array}{c}\text { Thermo- } \\
\text { Calc }\end{array}$ & $\begin{array}{c}\text { Equation } \\
(6 \mathrm{~b})\end{array}$ & $\begin{array}{c}\text { Thermo- } \\
\text { Calc }\end{array}$ \\
\hline$R^{2}$ & 0.946 & 0.928 & 0.925 & 0.914 \\
Standard deviations & 1.901 & 2.309 & -2.451 & 1.777 \\
Average value & 0.821 & 0.563 & 3.736 & 3.879 \\
Minimum & -2.700 & -2.200 & -10.501 & -3.000 \\
Maximum & 4.400 & 6.200 & 2.665 & 10.000 \\
\hline
\end{tabular}

alloying elements such as $\mathrm{Si}$ in $\mathrm{Al}-\mathrm{Si}$ alloys and $\mathrm{Al}$ in $\mathrm{Mg}-\mathrm{Al}$ alloys) or setting the maximal concentrations of other minor alloying elements that can be found in typical hypoeutectic $\mathrm{Al}$ and $\mathrm{Mg}$ alloys [30]. It means that, theoretically, the established liquidus equations for $\mathrm{Al}$ and $\mathrm{Mg}$ alloys are usable up to the eutectic concentrations of any elements present in these alloys. Tables 2 and 3 show only those alloys that are found in the available literature with measured liquidus temperatures. In addition, the higher cooling rates applied in the experimental data presented in Tables 2 and 3 are a potential source of inaccuracy that cannot be disregarded.

Another advantage of a new equivalency method can be recognized in its general application to calculate the liquidus temperatures of other alloys. Potentially, a similar approach could be used to develop an algorithm for the calculation of the solidus temperature of other light alloys.

\section{Conclusion}

In this paper, a new method of equivalency has been developed that is able to predict the liquidus temperatures of multicomponent aluminum and magnesium alloys based on known aluminum and magnesium binary phase diagrams. The new method of equivalency expresses the amounts of major and minor alloying elements in the aluminum/magnesium melts through an "equivalent" amount of a reference element. Statistical analysis of the results obtained for a wide range of alloy chemical compositions shows a very good correlation between the calculated and experimentally determined data. The newly developed method can be applied to calculate other characteristic solidification temperatures of nonferrous and ferrous multicomponent alloys.

\section{Acknowledgment}

This work is financially supported by the Ministry of Science and Technical Development, Serbia, Projects ON: 172005 and TR: 35023.

\section{References}

[1] G. Drossel, "Der einfluss von schmelzebehandlungen auf die dichtheit von gusskoerpon aus Al-Si Gusslegierungen," Giessereitechnik, vol. 27, pp. 7-12, 1981.

[2] R. Vijayaraghavan, N. Pelle, J. Boileau, J. Zindel, R. Beals, and F. Bradley, "A micro model for aluminium-silicon alloys," Scripta Materialia, vol. 35, pp. 861-867, 1996. 
[3] E. Schürmann, M. Djurdjevic, and L. Nedeljkovic, "Calculation of liquidus temperature of low and high alloyed iron base melts from their chemical composition by means of the equivalence factors," Steel Research, vol. 68, no. 3, pp. 101-106, 1997.

[4] ASM Handbook, Alloy Phase Diagrams, vol. 3, ASM International, Metals Park, Ohio, USA, 1992.

[5] J. Barthel, E. Buhrig, K. Hein, and L. Kucl, Kristallisation aus der Schmelze, VEB Deutscher Verlag für Grundstoffindustrie, Leipzig, Germany, 1983.

[6] V. S. Zolotorevsky and N. I. Belov, Casting Aluminum Alloys, Elsevier, Amsterdam, The Netherlands, 2007.

[7] A. R. E. Singer and S. A. Cottrell, "Properties of aluminumsilicon alloys at temperatures in the region of the solidus," Journal of the Institute of Metals, vol. 73, pp. 33-73, 1947.

[8] O. Berthon, G. Petot-Ervas, C. Petot, and P. Desre, "Thermodynamics of Al-Si Alloys containing from 2 to 35 at.\%Si," Comptes Rendus de l'Académie des Sciences, vol. 268, pp. C1939-C1942, 1969.

[9] L. Backerud, G. Chai, and J. Tamminen, Solidification Characteristics of Aluminum Alloys, vol. 2, AFS Skanaluminium, Schaumburg, Ill, USA, 1990.

[10] J. L. Murray, "The Al-Mg (Aluminum-Magnesium) system," Bulletin of Alloy Phase Diagrams, vol. 3, no. 1, pp. 60-74, 1982.

[11] A. A. Nayeb-Hashemi and J. B. Clark, Phase Diagrams of Binary Magnesium Alloys, ASM International, Metals Park, Ohio, USA, 1998.

[12] http://www.magmasoft.de/de/.

[13] http://www.thermocalc.com/.

[14] W. Cao, S. L. Chen, F. Zhang et al., "PANDAT software with pan engine, pan optimizer and pan precipitation for multicomponent phase diagram calculation and materials property simulation," Calphad, vol. 33, no. 2, pp. 328-342, 2009.

[15] http://www.factsage.com/.

[16] http://www.esi-group.com/products/casting/procast.

[17] http://www.calphad.org/.

[18] http://www.rwp-simtec.de/index.php?id=12.

[19] S.-C. Jeng and S.-W. Chen, "Determination of the solidification characteristics of the A356.2 aluminum alloy," Materials Science Forum, vol. 217-222, no. 1, pp. 283-288, 1996.

[20] K. Kobayashi, P. H. Shingu, and R. Ozaki, "Shift of aluminium liquidus in Al-Si system due to the sodium addition," Scripta Metallurgica, vol. 10, no. 6, pp. 525-527, 1976.

[21] B. P. Winter, T. R. Ostram, T. A. Sleder, P. K. Trojan, and R. D. Pehlke, "Mould dilation and volumetric shrinkage of aluminum alloys in green and dry sand molds," AFS Transactions, vol. 87, p. 259, 1993.

[22] A. Kearney, "Thermatest thermal analysis system for quality control of molten aluminum," in Proceedings of the Conference on Thermal Analysis of Molten Aluminum, p. 169, Rosemont, Ill, USA, 1984.

[23] J. Carbonier and C. Rechiney, "Foundry monitoring of aluminum alloys using thermal analysis," in Proceedings of the Conference on Thermal Analysis of Molten Aluminum, p. 121, Rosemont, Ill, USA, 1984.

[24] J. Morice, "History of thermal analysis and its application to aluminum alloy castings," in Proceedings of the Conference on Thermal Analysis of Molten Aluminum, p. 37, Rosemont, Ill, USA, 1984.

[25] M. B. Djurdjevic, S. Manasijevic, Z. Odanovic, and R. Radisa, "Influence of different contents of $\mathrm{Si}$ and $\mathrm{Cu}$ on the solidification pathways of cast hypoeutectic Al-(5-9)Si-(1-4)Cu (wt.\%) alloys," International Journal of Materials Research, no. 9, pp. 865-873, 2013.

[26] S. M. Liang, R. S. Chen, J. J. Blandin, M. Sueryand, and E. H. Han, "Thermal analysis and solidification pathways of Mg-AlCa system alloys," Materials Science and Engineering A, vol. 480, pp. 365-372, 2008.

[27] M. Ohno, D. Mirkovic, and R. Schmid-Fetzer, "Liquidus and solidus temperatures of Mg-rich Mg-Al-Mn-Zn alloys," Acta Materialia, vol. 54, no. 15, pp. 3883-3891, 2006.

[28] H. E. Friedrich and B. L. Mardike, Magnesium Technology, Springer, Heidelberg, Germany, 2006.

[29] W. Kasprzak, J. H. Sokolowski, M. Sahoo, and L. A. Dobrzański, "Thermal and structural characteristics of the AM50 magnesium alloy," Journal of Achievements in Materials and Manufacturing Engineering, vol. 28, no. 2, pp. 131-138, 2008.

[30] M. B. Djurdjevic, W. T. Kierkus, G. E. Byczynski, and J. H. Sokolowski, "Calculation of liquidus temperature for the Aluminum 3XX series of alloys," AFS Transactions, vol. 47, pp. 143-147, 1998. 

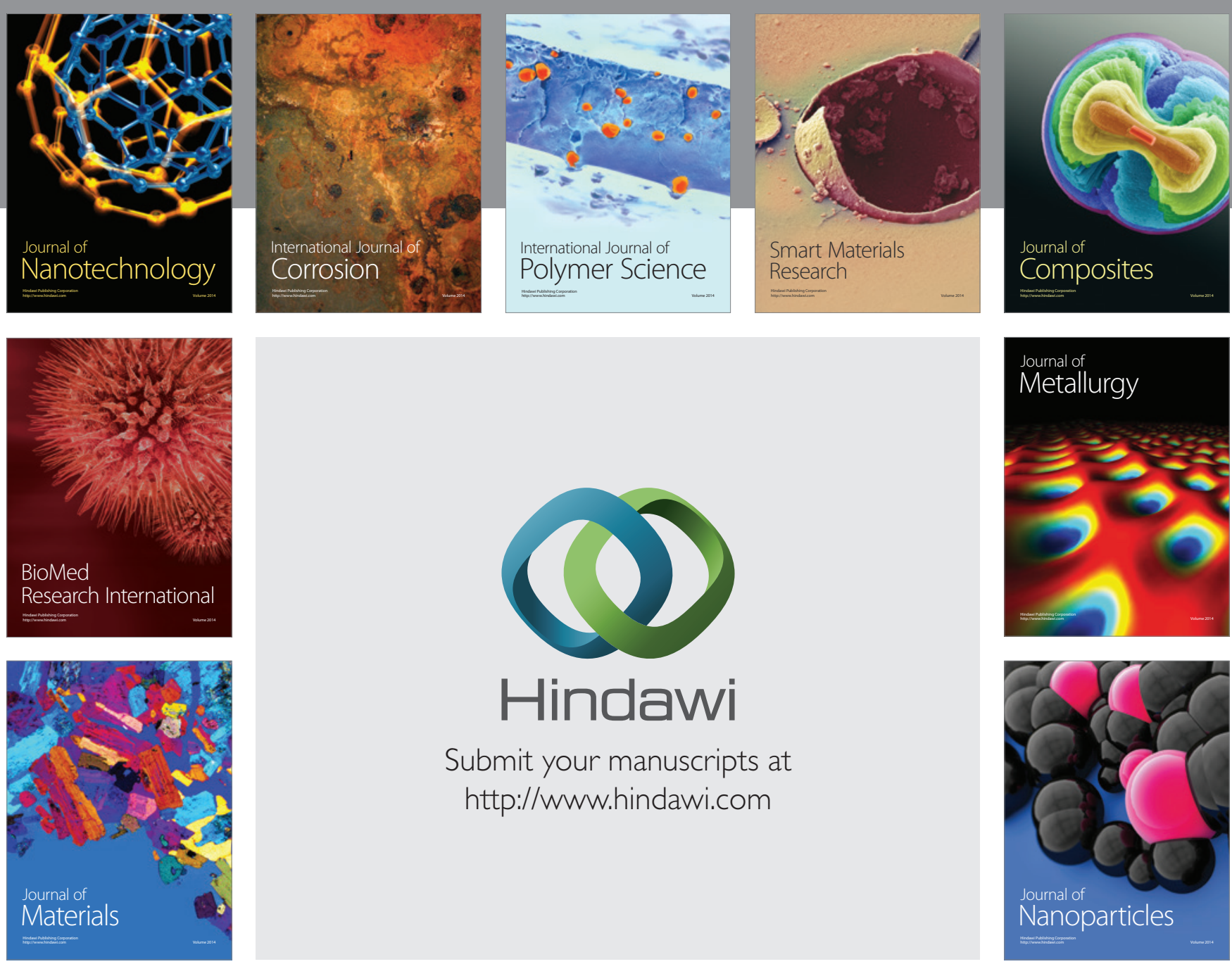

Submit your manuscripts at http://www.hindawi.com
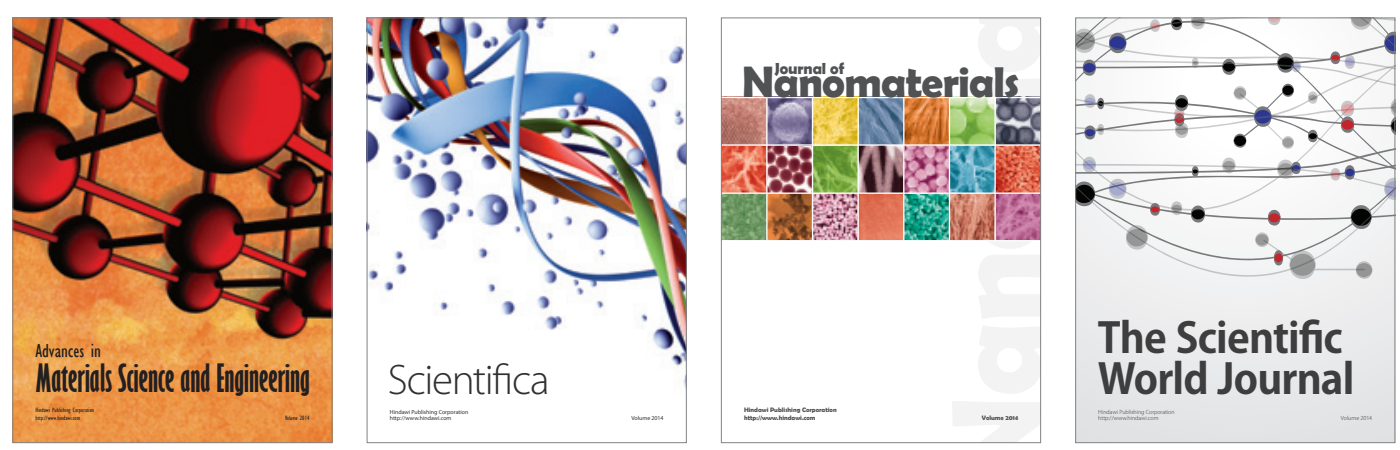

\section{The Scientific World Journal}
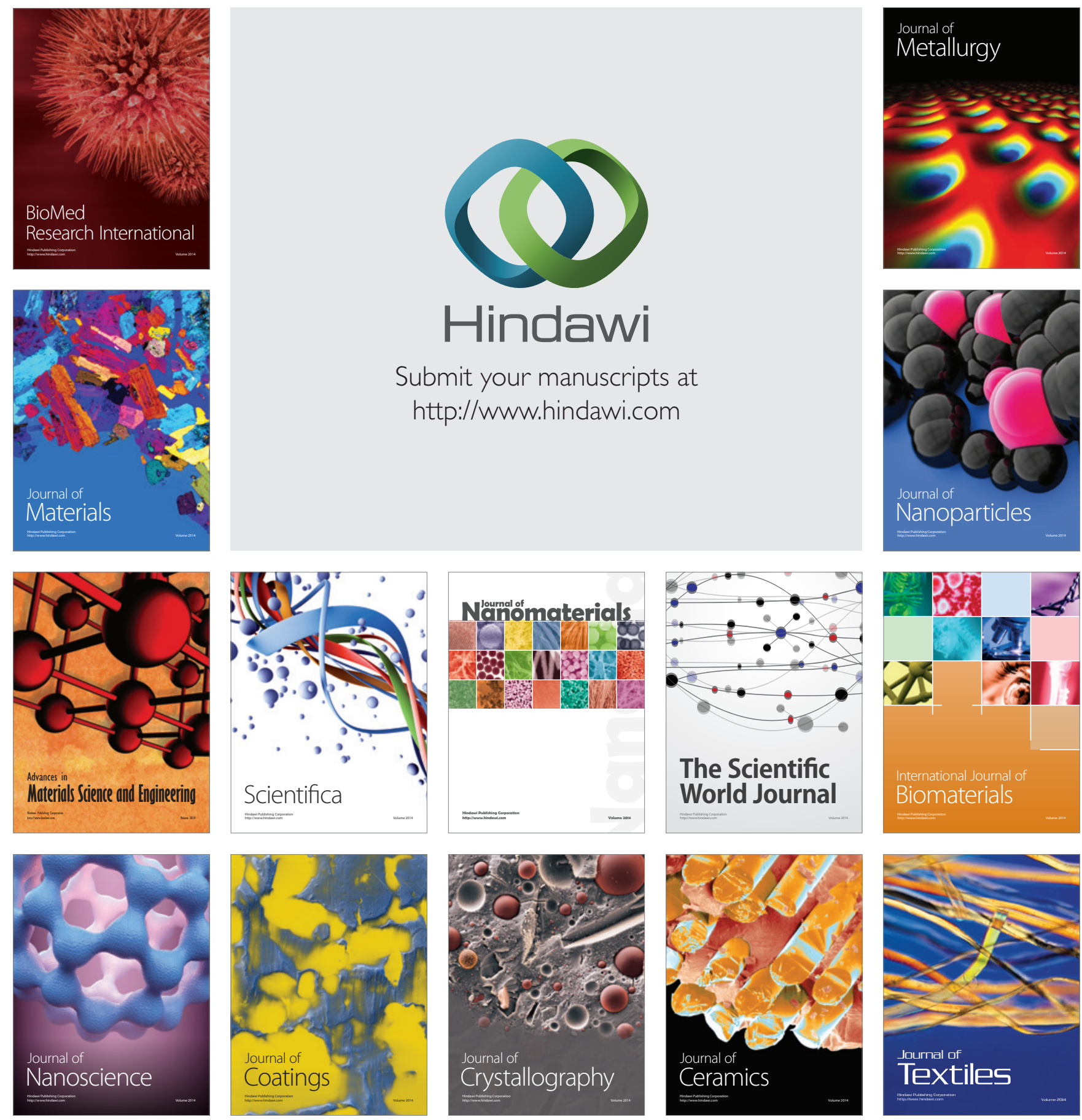